\title{
Preparation and Characterization of Maltose-Pendant Polymer/Mica Nanocomposites and Their Application to Oxygen Gas Barrier Films
}

\author{
Hideo Sakurai1,2, Shoji Nagaoka2,3*, Maki Horikawa2,3, Tomohiro Shirosaka2,3, \\ Shuzou Kubota4, Kazuhiro Hamada4, Makoto Takafuji 1,2, Hirotaka Ihara ${ }^{1,2}$ \\ ${ }^{1}$ Graduate School of Science and Technology, Kumamoto University, Kumamoto, Japan \\ ${ }^{2}$ Kumamoto Institute for Photo-Electro Organics (Phoenics), Kumamoto, Japan \\ ${ }^{3}$ Kumamoto Industrial Research Institute, Kumamoto, Japan \\ ${ }^{4}$ KOHJIN Film \& Chemicals Co., Ltd., Kumamoto, Japan \\ Email: nagaoka@kmt-iri.go.jp
}

Received 6 April 2014; revised 25 May 2014; accepted 10 June 2014

Copyright (C) 2014 by authors and Scientific Research Publishing Inc.

This work is licensed under the Creative Commons Attribution International License (CC BY).

http://creativecommons.org/licenses/by/4.0/

(c) (i)

\begin{abstract}
Maltose-pendant polymer/mica nanocomposites were prepared by a solution intercalation method. For organic composite part, 1) maltose-pendant polymer (homopolymer) and 2) the copolymer of maltose-pendant monomer and a small amount of $N, N$-Dimethylamino propylacrylamide, methyl chloride quartenary were used. The morphological studies (XRD and FE-SEM) revealed that the hybrid of maltose-pendant polymer was a conventional phase separated composite. On the other hand, the hybrid using the copolymer exhibited exfoliated structure. Both the conventional composite of maltose-pendant polymer and the nanocomposite of copolymer were applied to a coating material for oxygen gas barrier layer on a nylon- 6 film, and oxygen transmission rates of the films were evaluated. Maltose-pendant polymer had a good oxygen barrier property under dry condition, and the barrier property under wet condition was improved by the hybridization with mica. In contrast, the barrier property of copolymer was slightly inferior to that of maltosependant polymer. However, under dry condition, it can be seen that the nanocomposite of copolymer improves the barrier property more effectively than the case of conventional composite of maltose-pendant polymer.
\end{abstract}

\section{Keywords}

Maltose-Pendant Polymer, Nanocomposite, Mica, Oxygen Gas Barrier Film, Food Packaging

\footnotetext{
"Corresponding author.
}

How to cite this paper: Sakurai, H., et al. (2014) Preparation and Characterization of Maltose-Pendant Polymer/Mica Nanocomposites and Their Application to Oxygen Gas Barrier Films. Journal of Biomaterials and Nanobiotechnology, 5, 146-152. http://dx.doi.org/10.4236/ibnb.2014.53017 


\section{Introduction}

Oxygen gas barrier films have been widely used for food and pharmaceutical packaging in order to protect their contents from oxidation and denaturation. However, since these films have been produced in large quantities and have been disposed by incineration, development of materials must be attempted with considering the reduction of environmental load after use as well as the improvement of their barrier properties. Biodegradable polymer-based materials are, therefore, suitable for these packaging applications [1].

Cellulose (Cellophane), one of the most abundant natural resources, exhibits an oxygen gas barrier property under a dry condition. But the poor processability and the low solubility in common solvents originated from the tight inter- and intra-molecular hydrogen bonding have prevented the commercial applications of this material. Previously, in order to improve these drawbacks, our group synthesized water-soluble oligosaccharide-pendant polymers [2] [3]. These polymers are expected to retain the biodegradability, biocompatibility and the oxygen gas barrier property of cellulose.

In the present paper, we synthesized maltose-pendant polymer (Figure 1(a)), and applied to a coating material for an oxygen gas barrier layer on a nylon-6 film. Amongst oligosaccharides, maltose was employed because of its availability in large quantities. Subsequently, we hybridized maltose-pendant polymer with mica in order to improve the barrier property under a high humidity condition.

Polymer/clay nanocomposites, where nanometer-thin clay platelets are dispersed in polymer matrices, possess enhanced gas barrier properties, and hence they have been investigated in many laboratories [4]-[12]. The mechanism of barrier improvement is explained by using the tortuous path model [13] [14]. Clay platelets are naturally impermeable, and then diffusing gas molecules are forced to follow the tortuous path created by clay platelets. For this reason, clays having high aspect ratios are preferable for the effective retardation of gas penetration through polymer films [15].

In the present study, we used mica as inorganic filler, considering its high aspect ratio, over 1000. However, the charge density of mica platelets is high (about 1 equiv/mol), and platelets are tightly held together by electrostatic forces. Therefore, for the purpose of exfoliating mica platelets individually, we utilized the maltosependant polymer containing cationic groups as well (Figure 1(b)). The morphology of prepared hybrids was characterized by X-ray diffraction (XRD) analysis and field emission scanning electron microscope (FE-SEM) observation. The oxygen transmission rate (OTR) of hybrid-coated films was evaluated at three humidity conditions ( $0 \%, 50 \%$ and $90 \%$ ), and the effect of mica loading and the influence of polymers were investigated.

\section{Materials and Methods}

\subsection{Materials}

Maltose monohydrate and ammonium hydrogencarbonate were obtained from Wako Pure Chemical Industries, Ltd. (Osaka, Japan). 2-isocyanatoethyl methacrylate (2-IEM) was obtained from Showa Denko K. K. (Tokyo, Japan). $N, N$-Dimethylamino propylacrylamide, methyl chloride quartenary (DMAPAA-Q) was obtained from KOHJIN Film \& Chemicals Co., Ltd. (Tokyo, Japan). Ammonium peroxodisulfate (APS) and $N, N, N^{\prime}, N^{\prime}-\mathrm{Te}-$ traethylethylenediamine (TEEDAm) were obtained from Wako Pure Chemical Industries, Ltd. (Osaka, Japan) and KANTO CHEMICAL CO., INC. (Tokyo, Japan), respectively. Synthetic mica dispersion (NTS-10) was obtained from TOPY INDUSTRIES, LIMITED (Tokyo, Japan). All were used without purification.
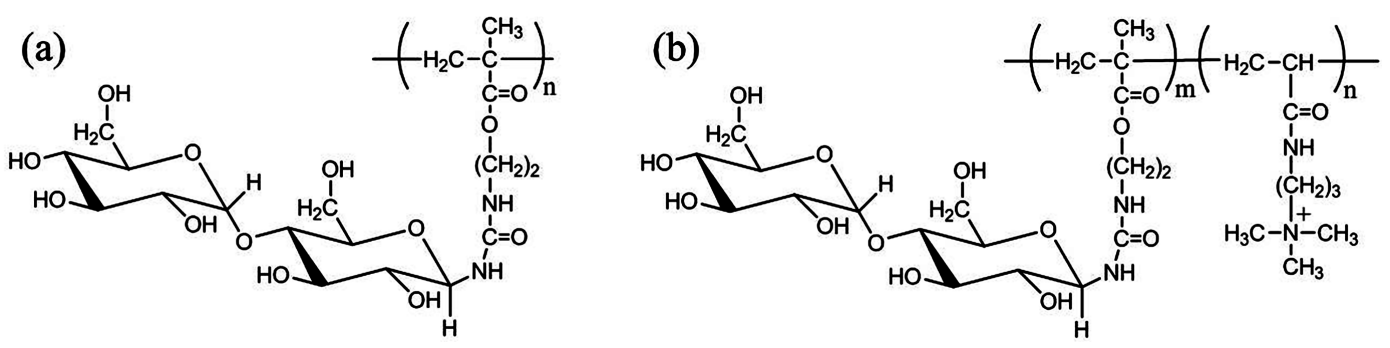

Figure 1. Chemical structures of a series of maltose-pendant polymers: (a) maltose-pendant polymer; (b) the copolymer of maltose-pendant monomer and DMAPAA-Q. 


\subsection{Synthesis of Maltose-Pendant Polymers}

Previously, our group prepared and characterized oligosaccharide-pendant polymers [2] [3]. In the present study, maltose-pendant polymer (MPP) was synthesized by the same method (Figure 2) [2]. A typical procedure is as follows.

Maltose monohydrate $(10.53 \mathrm{~g}, 29.22 \mathrm{mmol})$ was dissolved in water $\left(150 \mathrm{~cm}^{3}\right)$, and ammonium hydrogencarbonate (28.5 g) was added at intervals of $24 \mathrm{~h}$, and was stirred at $37^{\circ} \mathrm{C}$ for 4 days. The solution was diluted with water $\left(200 \mathrm{~cm}^{3}\right)$ and concentrated to $50 \mathrm{~cm}^{3}$. This procedure was repeated until the ammonia odor had disappeared. HPLC showed that the purity of freeze-dried product was $64.6 \%$.

The obtained maltosylamine (5.00 g, $9.50 \mathrm{mmol}$ ) was dissolved in a $1.0 \times 10^{-3} \mathrm{M} \mathrm{KOH}$ aqueous solution (100 $\mathrm{cm}^{3}$ ). 2-IEM (3.67 g, $23.7 \mathrm{mmol}$ ) was added to the solution and stirred at $3^{\circ} \mathrm{C}$ for $12 \mathrm{~h}$ with producing white precipitate as a by-product. This precipitate was removed by filtration. The filtrate was washed with diethyl ether in order to remove unreacted 2-IEM, and then freeze-dried. The crude product was dissolved in water/methanol and recrystallized from acetone/diethyl ether. The yield was $5.44 \mathrm{~g}$ (purity 76.4\%).

The synthesized maltose-pendant monomer $(3.80 \mathrm{~g}, 5.85 \mathrm{mmol})$ was dissolved in water $\left(20 \mathrm{~cm}^{3}\right)$. Air was degassed from the solution by nitrogen gas, and APS (13.3 mg, $0.0585 \mathrm{mmol})$ and TEEDAm (100.8 mg, 0.585 mmol) were added to the solution. The mixture was stirred at $0^{\circ} \mathrm{C}$ under nitrogen gas atmosphere for $3 \mathrm{~h}$. The obtained crude polymer was purified by dialyzing in a dialysis tube (Spectra/por 3, Spectrum Laboratories, Inc.) for 3 days in order to remove unreacted monomer. The product was finally freeze-dried, giving a white powdery polymer. The yield was $2.21 \mathrm{~g}$.

The maltose-pendant polymer containing cationic groups, that is, the copolymer of maltose-pendant monomer and a small amount of DMAPAA-Q was also synthesized by the similar method. The mole percent of DMAPAA-Q in polymerization process was chosen to be $5 \mathrm{~mol} \%$ and $10 \mathrm{~mol} \%$. Hereafter, these synthesized copolymers are termed CP5 and CP10, respectively.

\subsection{Preparation of Maltose-Pendant Polymer/Mica Hybrid-Coated Films}

We prepared maltose-pendant polymer/mica hybrids by a solution intercalation method. Maltose-pendant polymer/mica hybrid solutions were prepared by mixing of a $5 \mathrm{wt} \%$ maltose-pendant polymer aqueous solution and a $5 \mathrm{wt} \%$ mica dispersion in a determined ratio, and after which sonic was irradiated for 5 min. Each obtained hybrid solution was cast on a corona-treated nylon- 6 film. The thickness of solution was controlled by the wire bar (wire diameter $=0.75 \mathrm{~mm}$ ). After drying at $100^{\circ} \mathrm{C}$ for $30 \mathrm{~s}$, the films were heat-treated at $210^{\circ} \mathrm{C}$ for $15 \mathrm{~s}$.

\subsection{Characterization}

The morphology of maltose-pendant polymer/mica hybrids was studied by using XRD analysis and FE-SEM observation. The basal spacing of hybrids was evaluated by Rigaku diffractometer with $\mathrm{CuK} \alpha$ radiation operated at $45 \mathrm{kV}$ and $200 \mathrm{~mA}$. Samples for XRD analysis were prepared by freeze-drying of hybrid solutions. The surfaces of hybrids were observed by Hitachi SU8000 scanning electron microscope using an acceleration voltage of $5 \mathrm{kV}$. Samples for FE-SEM observation were prepared by drying of hybrid solutions at $100^{\circ} \mathrm{C}$ in petri dishes. The OTR of hybrid-coated films was evaluated using Oxygen Permeation Analyzer 8001 (Systech Illi-

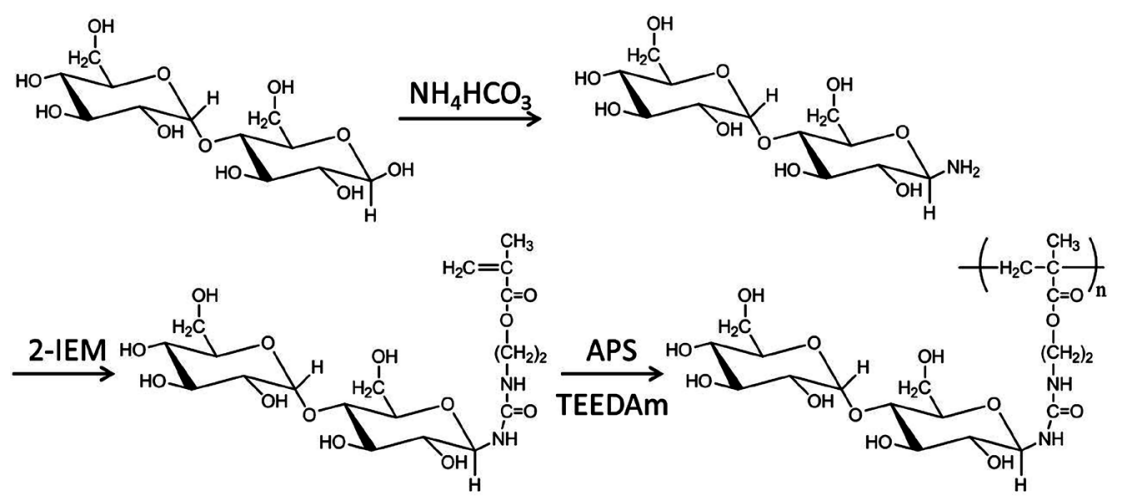

Figure 2. Synthesis of maltose-pendant polymer (MPP). 
nois) at three relative humidity conditions, $0 \%, 50 \%$ and $90 \%$.

\section{Results and Discussion}

\subsection{Molecular Weights of Maltose-Pendant Polymers}

The molecular weights of synthesized maltose-pendant polymers were determined by size exclusion chromatography (SEC) using a Shodex SB-806M HQ column. The SEC calibration curve was prepared by a pullulan standard (Shodex STANDARD P-82). We used $10 \mathrm{mM}$ lithium bromide ( $\mathrm{LiBr}$ ) aqueous solution as an eluent in order to prevent aggregations of the polymers. As shown in Table 1, synthesized polymers have weightaveraged molecular weights of 280,000 - 960,000 and number-averaged molecular weights of 46,000 210,000. The molecular weights of CP10 couldn't be obtained, because of the adsorption toward the column packing. Instead, we synthesized the copolymer CP1 and evaluated the molecular weights of this copolymer. These values indicate that the molecular weights of maltose-pendant polymers decrease with increasing the ratio of DMAPAA-Q.

\subsection{Morphology}

Figure 3 shows the XRD patterns of mica powder and a series of maltose-pendant polymers hybrids with mica at $10 \mathrm{wt} \%$ loading. MPP/Mica10 ${ }^{1}$ hybrid has a diffraction peak at $2 \theta=6.73^{\circ}(\mathrm{d}$ spacing $=13.1 \AA$ ), which is almost the same as that of mica powder $\left(2 \theta=7.07^{\circ}\right.$, $\mathrm{d}$ spacing $\left.=12.5 \AA\right)$. This indicates that mica is dispersed as tactoids within the MPP matrix. In contrast, the copolymer hybrids, CP5/Mica10 and CP10/Mica10 don't show any diffraction peak in $2 \theta=3^{\circ}-10^{\circ}$, suggesting that ammonium cations of these copolymers promote the exfoliation of negatively charged mica platelets.

The FE-SEM observation supports the result of XRD analysis. Figure 4 compares the surfaces of MPP/Mica10, CP5/Mica10 and CP10/Mica10 hybrids. The dark regions represent polymers, and grey parts are micapla-

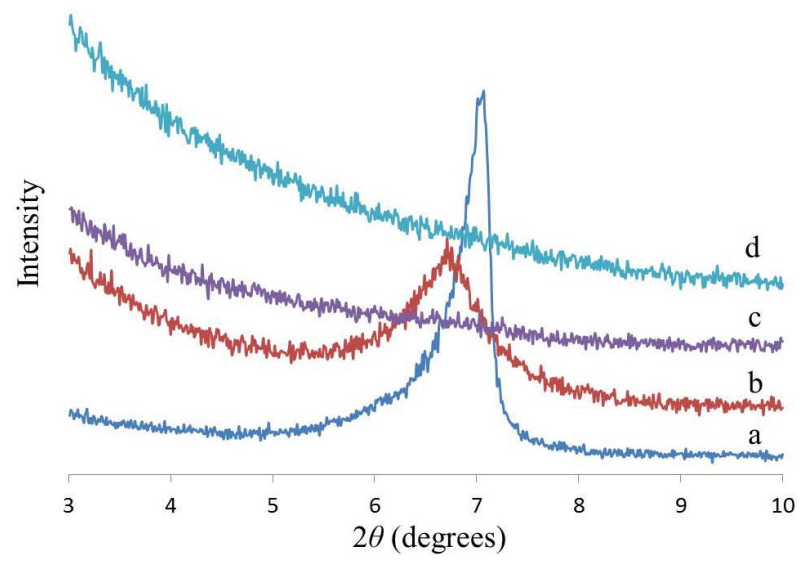

Figure 3. XRD patterns of (a) mica powder; (b) MPP/Mica10; (c) CP5/Mica10; and (d) CP10/Mica10.

Table 1. Molecular weights of maltose-pendant polymers.

\begin{tabular}{cccc}
\hline Compound code & $\mathrm{M}_{\mathrm{w}}\left(\times 10^{5}\right)$ & $\mathrm{M}_{\mathrm{n}}\left(\times 10^{5}\right)$ & $\mathrm{M}_{\mathrm{w}} / \mathrm{M}_{\mathrm{n}}$ \\
\hline MPP & 9.59 & 2.09 & 4.59 \\
CP1 & 5.25 & 1.39 & 3.77 \\
CP5 & 2.84 & 0.46 & 6.12 \\
CP10 & - & - & - \\
\hline
\end{tabular}

aThe peak of chromatogram was very weak, and molecular weights of CP10 couldn't be evaluated.

\footnotetext{
${ }^{1}$ The number at the end of word represents the loading of mica (wt\%). For Example, CP1/Mica5 is the hybrid of copolymer (DMAPAA-Q, $1 \mathrm{~mol} \%$ ) with mica at $5 \mathrm{wt} \%$ loading.
} 

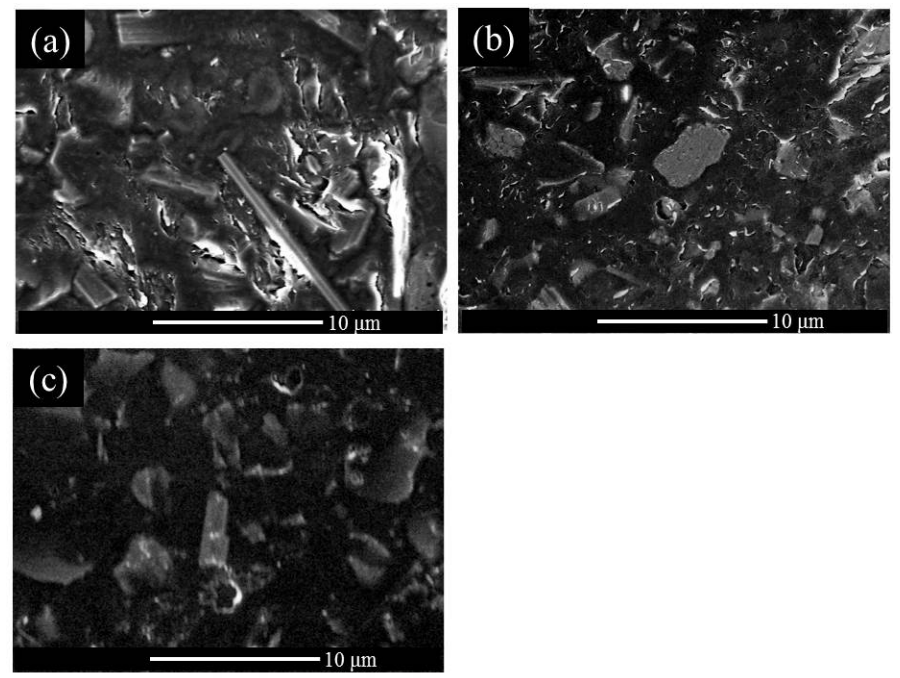

Figure 4. FE-SEM images of the surfaces of (a) MPP/Mica10 hybrid; (b) CP5/Mica10 hybrid; and (c) CP10/Mica10 hybrid.

telets. The surface of MPP/Mica10 is coarse, and which can be attributed to the phase separated structure as confirmed by XRD. On the other hand, the CP5/Mica10 and CP10/Mica10 reveal the smooth surfaces, suggesting that mica platelets are remarkably compatible with these positively charged copolymers. In conclusion, MPP/Mica10 belongs to a conventional phase separated composite, and we expect that exfoliated nanocomposites are obtained for CP5/Mica10 and CP10/Mica10 hybrids.

\subsection{Oxygen Gas Barrier Properties of Maltose-Pendant Polymer/Mica Hybrid-Coated Films}

In general, oxygen gas barrier properties of polymer films are correlated to their crystallinity. Since water molecules act as a plasticizer, their barrier performance decrease with the increase of humidity level. Therefore, we observed the OTR of prepared films at three relative humidity conditions, $0 \%, 50 \%$ and $90 \%$ (Table 2).

First, we evaluated the OTR of non-coated nylon-6 film. The tolerable value of OTR in the food packaging application is considered to be $10 \mathrm{~cm}^{3} \cdot \mathrm{m}^{-2} \cdot \mathrm{d}^{-1} \cdot \mathrm{atm}^{-1}$. Table 2 shows that the OTR of non-coated nylon- 6 film is $119 \mathrm{~cm}^{3} \cdot \mathrm{m}^{-2} \cdot \mathrm{d}^{-1} \cdot \mathrm{atm}^{-1}$ at RH $90 \%$ condition, revealing that the demand level of food packaging is not satisfied by the nylon- 6 film alone. Another feature is that this nylon- 6 film has its minimum OTR value at RH $50 \%$ condition $\left(21.8 \mathrm{~cm}^{3} \cdot \mathrm{m}^{-2} \cdot \mathrm{d}^{-1} \cdot \mathrm{atm}^{-1}\right)$. This humidity dependence was already studied (e.g., [16]), and can be explained in terms of the extent of interaction between water molecules and molecular chains of nylon- 6 . That is, under RH 50\% condition a small amount of water molecules suppress the motion of molecular chains, and hence oxygen gas permeation is reduced.

For the hybrid of MPP, we employed the loading of mica a little higher (10 wt $\%$ - $30 \mathrm{wt} \%$ ), because this hybrid took a conventional phase separated structure as confirmed in morphological studies. For simplification, the supersonic irradiation process of a mixed hybrid solution was omitted. As shown in Table 2, MPP coating improved the oxygen barrier property of nylon-6 film under dry condition, and the OTR was $0.93 \mathrm{~cm} \cdot \mathrm{m}^{-2} \cdot \mathrm{d}^{-1} \cdot \mathrm{atm}^{-1}$ at RH $0 \%$. The barrier property of MPP can be explained by the inter- and intramolecular hydrogen bonding between adjacent maltose units. Under wet condition, the barrier property is improved by the hybridization with mica. Especially, the OTR of MPP/Mica20 and MPP/Mica30-coated films are reduced to less than 10.0 $\mathrm{cm}^{3} \cdot \mathrm{m}^{-2} \cdot \mathrm{d}^{-1} \cdot \mathrm{atm}^{-1}$ even at RH $90 \%$ condition. This indicates that these films have a potential to be usable in the food packaging field.

The barrier properties of polymer/clay hybrids are enhanced by finely dispersed impermeable clay particles. The extent of enhancement depends on the interfacial area between polymer matrix and clay particles. We introduced the cationic groups into maltose-pendant polymer in order to exfoliate negatively charged mica platelets individually. The morphological studies suggested that the exfoliated structures were obtained for these copolymer hybrids. Table 2 shows that the oxygen gas barrier properties of copolymer coated films were not bet- 
Table 2. Oxygen transmission rate (OTR) of maltose-pendant polymer/mica hybrid-coated films.

\begin{tabular}{cccc}
\hline & \multicolumn{3}{c}{ OTR in each humidity $\left(\mathrm{cm}^{3} \cdot \mathrm{m}^{-2} \cdot \mathrm{d}^{-1} \cdot \mathrm{atm}^{-1}\right)$} \\
\cline { 2 - 4 } Coating agent & $0 \%$ & $50 \%$ & $90 \%$ \\
\hline$-^{\mathrm{a}}$ & 48.8 & 21.8 & 119 \\
MPP & 0.93 & 14.2 & Over 70 \\
MPP/Mica10 & 0.56 & 0.54 & 12.7 \\
MPP/Mica20 & 0.19 & 0.59 & 9.52 \\
MPP/Mica30 & 0.13 & 0.10 & 7.63 \\
CP5 & & & 86.5 \\
CP5/Mica5 & 3.60 & 4.20 & 81.4 \\
CP5/Mica10 & 0.50 & 1.40 & 75.8 \\
& 0.10 & 0.80 & 103 \\
CP10 & & & 73.9 \\
CP10/Mica5 & 5.40 & 10.1 & 101 \\
CP10/Mica10 & 2.40 & 5.30 & \\
\hline
\end{tabular}

${ }^{a}$ Nylon-6 film. The drying and heat-treatment processes were abbreviated.

ter than that of MPP coated film except for RH 50\% condition. In addition, under RH 90\% condition, these barrier properties were not improved by the hybridization with mica. For example, the OTR of CP5 coated film was $86.5 \mathrm{~cm}^{3} \cdot \mathrm{m}^{-2} \cdot \mathrm{d}^{-1} \cdot \mathrm{atm}^{-1}$ under RH $90 \%$ condition, and that of CP5/Mica10 coated film was $75.8 \mathrm{~cm}^{3} \cdot \mathrm{m}^{-2} \cdot \mathrm{d}^{-1} \cdot \mathrm{atm}^{-1}$. These results can be attributed to the lowering of crystallinty and the increase of hygroscopy brought by copolymerization with DMAPAA-Q. In contrast, under dry condition, the oxygen gas barrier property was remarkably improved by the hybridization with mica. For example, the OTR value of CP5 coated film, 3.60 $\mathrm{cm}^{3} \cdot \mathrm{m}^{-2} \cdot \mathrm{d}^{-1} \cdot \mathrm{atm}^{-1}$ was reduced to $0.10 \mathrm{~cm}^{3} \cdot \mathrm{m}^{-2} \cdot \mathrm{d}^{-1} \cdot \mathrm{atm}^{-1}$ by the hybridization with mica at only $10 \mathrm{wt} \%$ loading. Considering the corresponding values of MPP system $\left(0.93\right.$ and $\left.0.56 \mathrm{~cm}^{3} \cdot \mathrm{m}^{-2} \cdot \mathrm{d}^{-1} \cdot \mathrm{atm}^{-1}\right)$, we can conclude that the exfoliation of mica platelets enhances the gas barrier property efficiently under dry condition.

\section{Conclusions}

In this study, maltose-pendant polymer/mica nanocomposites were prepared, and their oxygen gas barrier properties were investigated. The XRD analysis and FE-SEM observation revealed that the hybrid of maltose-pendant polymer (homopolymer) was a conventional phase separated composite, and that nanocomposites with exfoliated structures were achieved by using the copolymer of maltose-pendant monomer and DMAPAA-Q. This result indicates that introduction of cationic groups into polymer chains is an effective method for exfoliating negatively charged mica platelets individually. The oxygen gas barrier films were prepared by casting these conventional composite or nanocomposite on a nylon-6 film. Maltose-pendant polymer improved the oxygen gas barrier property under dry condition. The barrier property under wet condition was improved by the hybridization with mica. The OTR at RH $90 \%$ condition was reduced to $7.63 \mathrm{~cm}^{3} \cdot \mathrm{m}^{-2} \cdot \mathrm{d}^{-1} \cdot \mathrm{atm}^{-1}$ at $30 \mathrm{wt} \%$ mica loading, indicating that this material has a potential to be applied to the food packaging field. The barrier properties of copolymers were not better than that of maltose-pendant polymer. However, the effects of dispersion at nano level were confirmed under dry condition.

\section{References}

[1] Park, H.-M. and Ha, C.-S. (2009) Barrier Properties of Biodegradable Nanocomposites. In: Mittal, V., Ed., Barrier 
Properties of Polymer Clay Nanocomposites, Nova Science Publishers, Inc., New York, 231-256.

[2] Satoh, T., Nagaoka, S., Sakurai, T., Takafuji, M. and Ihara, H. (2005) Preparation of Spherical Nano Particles Using Novel Oligosaccharide Pendant Polymers and Their Characterization. Transactions of the MRS-Japan, 30, 1139-1142.

[3] Satoh, T., Nagaoka, S. and Ihara, H. (2005) Self-Assembled Nanoparticles from Oligosaccharide-Pendant Amphiphilic Polymers. Proceeding of the 8th International Symposium on Polymers for Advanced Technologies, Budapest, 13-16 September 2005.

[4] Park, H.-M., Lee, W.-K., Park, C.-Y., Cho, W.-J. and Ha, C.-S. (2003) Environmentally Friendly Polymer Hybrids. Part I Mechanical, Thermal, and Barrier Properties of Thermoplastic Starch/Clay Nanocomposites. Journal of Materials Science, 38, 909-915. http://dx.doi.org/10.1023/A:1022308705231

[5] Park, H.-M., Misra, M., Drzal, L.T. and Mohanty, A.K. (2004) “Green” Nanocomposites from Cellulose Acetate Bioplastic and Clay: Effect of Eco-Friendly Triethyl Citrate Plasticizer. Biomacromolecules, 5, 2281-2288. http://dx.doi.org/10.1021/bm049690f

[6] Ray, S.S., Yamada, K., Okamoto, M., Ogami, A. and Ueda, K. (2003) New Polylactide/Layered Silicate Nanocomposites. 3. High-Performance Biodegradable Materials. Chemistry of Materials, 15, 1456-1465. http://dx.doi.org/10.1021/cm020953r

[7] Cabedo, L., Feijoo, J.L., Villanueva, M.P., Lagarón, J.M. and Giménez, E. (2006) Optimization of Biodegradable Nanocomposites Based on aPLA/PCL Blends for Food Packaging Applications. Macromolecular Symposia, 233, 191-197. http://dx.doi.org/10.1002/masy.200690017

[8] Messersmith, P.B. and Giannelis, E.P. (1995) Synthesis and Barrier Properties of Poly(E-Caprolactone)-Layered Silicate Nanocomposites. Journal of Polymer Science Part A: Polymer Chemistry, 33, 1047-1057. http://dx.doi.org/10.1002/pola.1995.080330707

[9] Gorrasi, G., Tortora, M., Vittoria, V., Pollet, E., Lepoittevin, B., Alexandre, M. and Dubois, P. (2003) Vapor Barrier Properties of Polycaprolactone Montmorillonite Nanocomposites: Effect of Clay Dispersion. Polymer, 44, 2271-2279. http://dx.doi.org/10.1016/S0032-3861(03)00108-3

[10] Gorrasi, G., Tortora, M., Vittoria, V., Pollet, E., Alexadre, M. and Dubois, P. (2004) Physical Properties of Poly( $\varepsilon$-Caprolactone) Layered Silicate Nanocomposites Prepared by Controlled Grafting Polymerization. Journal of Polymer Science Part B: Polymer Physics, 42, 1466-1475. http://dx.doi.org/10.1002/polb.20042

[11] Xu, R., Manias, E., Snyder, A.J. and Runt, J. (2001) New Biomedical Poly(Urethane Urea)-Layered Silicate Nanocomposites. Macromolecules, 34, 337-339. http://dx.doi.org/10.1021/ma0013657

[12] Osman, M.A., Mittal, V., Morbidelli, M. and Suter, U.W. (2003) Polyurethane Adhesive Nanocomposites as Gas Permeation Barrier. Macromolecules, 36, 9851-9858. http://dx.doi.org/10.1021/ma035077x

[13] Yano, K., Usuki, A., Okada, A., Kurauchi, T. and Kamigaito, O. (1993) Synthesis and Properties of Polyimide-Clay Hybrid. Journal of Polymer Science Part A: Polymer Chemistry, 31, 2493-2498. http://dx.doi.org/10.1002/pola.1993.080311009

[14] Pavlidou, S. and Papaspyrides, C.D. (2008) A Review on Polymer-Layered Silicate Nanocomposites. Progress in Polymer Science, 33, 1119-1198. http://dx.doi.org/10.1016/j.progpolymsci.2008.07.008

[15] Cussler, E.L., Hughes, S.E., Ward III, W.J. and Aris, R. (1988) Barrier Membranes. Journal of Membrane Science, 38, 161-174. http://dx.doi.org/10.1016/S0376-7388(00)80877-7

[16] Khanna, Y.P., Day, E.D., Tsai, M.L. and Vaidyanathan, G. (1997) Re-Examining the Oxygen Barrier of Nylon 6 Films. I. Role of Moisture and Processing Induced Variables. Journal of Plastic Film and Sheeting, 13, 197-211. 
Scientific Research Publishing (SCIRP) is one of the largest Open Access journal publishers. It is currently publishing more than 200 open access, online, peer-reviewed journals covering a wide range of academic disciplines. SCIRP serves the worldwide academic communities and contributes to the progress and application of science with its publication.

Other selected journals from SCIRP are listed as below. Submit your manuscript to us via either submit@scirp.org or Online Submission Portal.
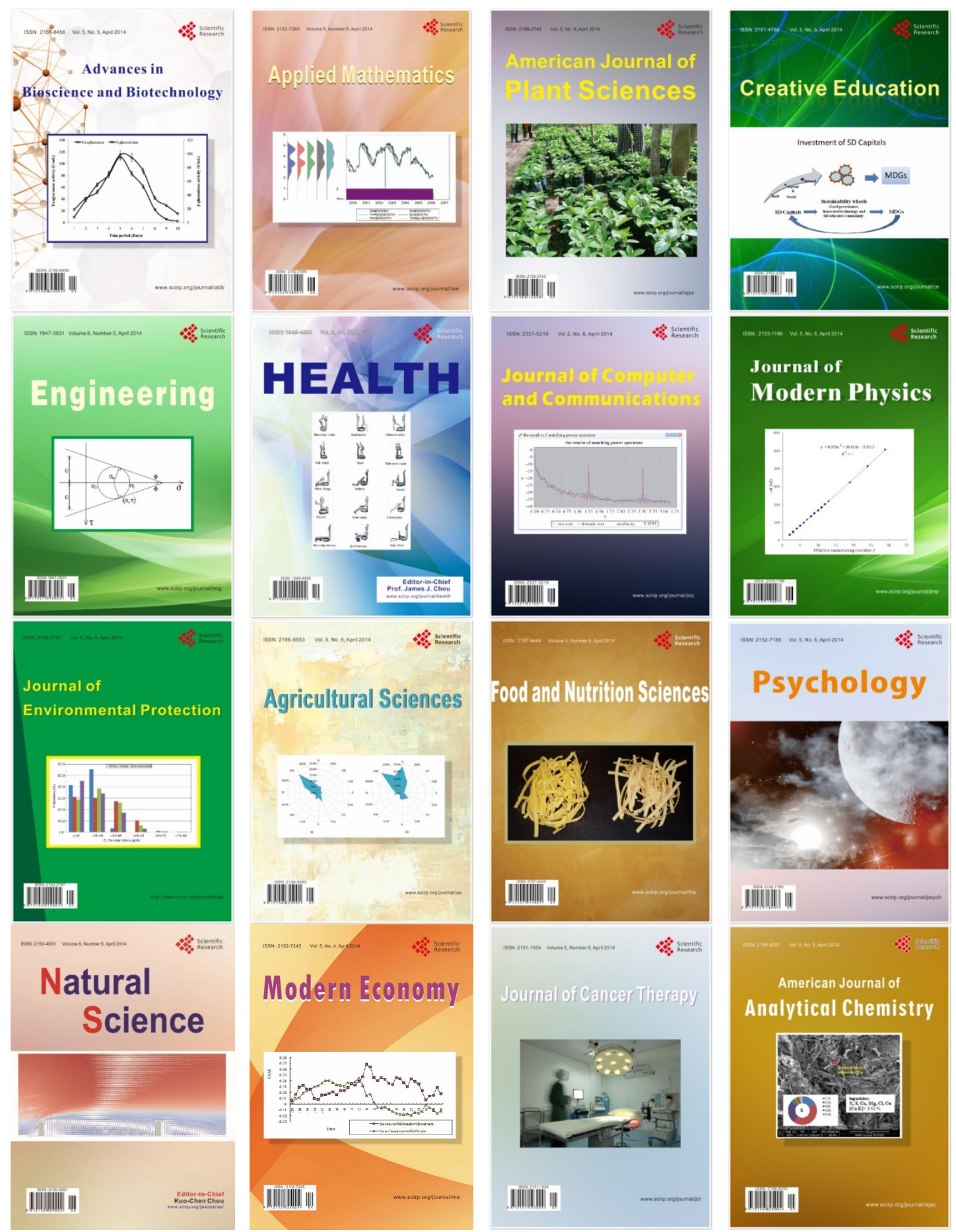